Ltd. In 1941 he left the works in order to establish the new Wellcome Chemical Research Laboratories at Beckenham. Here, after setting up temporary laboratories, he was responsible for the planning and development of the extensive permanent laboratories opened in 1946.

\section{A 7 Giant Meteorite}

IN the issue of L'Astonnomie for October 1948 there is an account of 3 enormous meteorite which, on February 12, 1847, fell in the Sihot-Alin chain of mountaif 0 in the vicinity of the Amoor River, Fastern Siberia. M. Krynov, secretary of the Comnission "of Meteorites of the Academy of Sciences df the U.S.S.R., who took part in the expedition which investigated the nature of the phencmenon, states that this meteorite is probably one of the largest that has ever struck the earth, and M. Fessenkov, who presides at the work conducted on meteorites, believes that the object was a minor planet. The fall was observed by the inhabitants of towns and villages over a radius of 200 kilcmetres around the place of impact, and those who were questioned agree that the body was moving from north to south, that its time of flight was between four and five seconds, and that it was more brilliant than the sun which was then shining on a beautiful morning in a clear sky. The noise of the fall and of a series of explosions which accompanied the flight of the object could be heard at distances of $200 \mathrm{~km}$. Preliminary estimates of its mass give this as about a thousand tons.

It has been estimated that the speed of the meteorite was about 20 kilometres a second and that its surface temperature, acquired by friction with the atmosphere, was of the order of $5,000^{\circ} \mathrm{C}$. It broke up into thousands of fragments of various sizes, and these lost their speed by friction with the atmosphere, falling on the earth merely by its gravitational att raction. Pieces were found over an area representea by a circle of $12 \mathrm{~km}$. radius. In an oval sector of $0.75 \mathrm{sq}$. $\mathrm{km}$. the members of the expedition found more than a hundred funnels in the rocks, caused by the fall of the debris, the diameters of these funnels varying from 0.5 to $28 \mathrm{~m}$., and some of them attained a depth of $6 \mathrm{~m}$. All around were found trees overthrown or damaged, and a number of large cedars were found split in two. On examining very carefully the neighbourhood of the fall, the expedition of 1947 discovered 257 fragments of the meteorite, varying in weight between $0.16 \mathrm{gm}$. and 1.8 tons, and about 5 tons of cosmic iron were collected, while the next expedition in 1948 collected about 4 tons more. Aerial photographs of the region were taken during 1948, and about $48 \mathrm{sq}$. $\mathrm{km}$. have been declared a closed district and placed at the disposal of the Aeadomy of Sciences of the U.S.S.R. for five years. Jurassic Holostei

THe questions of the clalsifigation of the fishes and of the interrelationships of the different groups are occupying the attention modern zoologists. In such a study thigh irvoltes fossil forms, a consideration of the bon of the sull and their homologies mist day an fmploxtant part. The dermal bones, amoplg other sklibtal structures, are often quite well preserved and so have received much attention. On the other hand, the neurocrania, being partly obscured by the dermal bones and only capable of study in particularly well-preserved specimens, are nothing like so well known although quite important. Hence the interest of a study of the neurocrania of some Jurassic Holostei recently made by Dr. Dorothy $H$. Rayner (Phil. Trans. Roy. Soc., B, 601; 1948). A special technique involving the grinding of the specimen and the taking of a series of transfers $0.1 \mathrm{~mm}$. apart was elaborated from a previous method suggested by E. C. Case in 1937. An appendix describes the technique fairly fully, and it will prob. ably be of use in other lines of work involving the sectioning and reconstruction of fossil material. In spite of considerable variation in the neurocranial ossifications, which differ among closely related forms and apparently in the same species with difference of age, there is, save in the supraoccipital and postotic regions, sufficient similarity to allow of broad homologies being drawn. This and other evidence adduced suggests that the Jurassic Holostei may be regarded as a natural group. Two particular points may be noted. There is sufficient similarity between the neurocrania of the Jurassic Lepidotus and the living Lepidosteus to suggest relationship between them, and in Caturus and Dapedius there is a lateral cranial canal without external opening to which, at present, no function can be assigned.

Mental Health and World Citizenship<smiles>[Li]</smiles>

The World Folergeron for Mental Health has pub. lished as a boollvet a statement produced by the Internation al pleparatory Commission for the Inter. national Copress of Mental Health which met in Lonfon it Mugust 1948. Although the statement will appenen in the published Proceedings of the Congress, the expressed wish that it should be given a wide circulation has resulted in its production in the present form. The International Preparatory Commission sat for a fortnight prior to the Congress and was made up of twenty-four persons from ten different countries representing the points of view of sociology, psychology, psychiatry, social work, anthropology, political science, philosophy and theology. As the raw material for its deliberations, reports were available from three hundred preparatory commissions composed of about five thousand workers in the different fields who had been working during the preceding year in twenty-seven countries. The booklet is obtainable from H. K. Lewis and Co., It.d., 136 Gower Street, London, W.C.1.

\section{Family Health Service in South Africa 3/s}

THE curren irsue of Biology and Human Affairs (14, No. 2; A tumn 1948) contains an article on the Family Hdah Service in South Africa, where twenty health centues have been established in various parts of The duntry by the Ministry of Health. A descrip. tion is given of the Polela Health Centre which was set up in 1940 in a rural native reserve in southwestern Natal. The family health service was first applied to a small area within the reserve and was gradually extended until, within four years, almost six thousand people were included in the scheme. This has led to a marked improvement in the health indices in that part of Polela where the family health service is in operation, and other health services have now been planned for the reserve, so extending the facilities to the entire population of the area. The article contains a detailed account of the way in which the service has been organised.

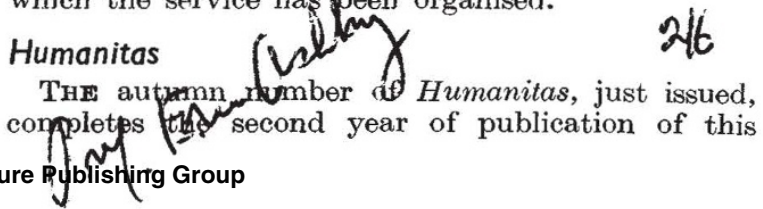

